\title{
BRASIL Y CHILE: DIVERSAS ESTRATEGIAS DE INTEGRACIÓN COMERCIAL, DIFERENTES LEYES Y POLÍTICAS DE PROPIEDAD INDUSTRIAL*
}

\section{BRAZIL AND CHILE: SEVERAL STRATEGIES OF COMMERCIAL INTEGRATION; DIFFERENT INDUSTRIAL PROPERTY LAWS AND POLICIES}

\author{
Helder Binimelis-Espinoza** \\ Fecha de recepción: 3 de marzo de 2015 \\ Fecha de aceptación: 21 de julio de 2015 \\ Disponible en linea: 30 de noviembre de 2015
}

\section{Para citar este artículo/To cite this article}

\author{
Binimelis-Espinoza, Helder, Brasil y Chile: Diversas estrategias de inte- \\ gración comercial, diferentes leyes y políticas de propiedad industrial, 131 \\ Vniversitas, 195-230 (2015). http://dx.doi.org/10.11144/Javeriana.vj131.bcde \\ doi:10.11144/Javeriana.vj131.bcde
}

* Este artículo presenta resultados de investigación para la obtención del grado de doctor en investigación en ciencias sociales con mención en sociología en la Facultad Latinoamericana de Ciencias Sociales, sede académica de México, FLACSO México. La investigación se efectuó dentro del grupo de investigación Sociedad del Conocimiento, Innovación y Redes durante el período 2008-2011.

** Docente, Universidad Católica de Temuco, Temuco, Chile. Magíster en estudios sociales y políticos latinoamericanos (Instituto Latinoamericano de Doctrina y Estudios Sociales, ILADES., Universidad Alberto Hurtado, Chile). Doctor en investigación en ciencias sociales con mención en sociología (FLACSO, México). Contacto: hbinimelis@uct.cl 


\section{RESUMEN}

En la actualidad, hay una doble tendencia en materia de propiedad intelectual. Por una parte, un giro desde una lógica del derecho a una comercial, en la medida en que los acuerdos internacionales de propiedad intelectual se firman como "anexos" de acuerdos y tratados internacionales, y no como acuerdos legales autónomos. Por otra parte, una tendencia a la homogeneización de las leyes de propiedad intelectual orientadas a una mayor rigurosidad en plazos de protección y sanciones legales, sin tomar en cuenta las diferencias de países con estructuras productivas diversas, y sin evaluar el impacto de la propiedad intelectual en procesos de desarrollo. A partir de la observación de los casos de Brasil y Chile (acuerdos comerciales internacionales, leyes y políticas de propiedad industrial), se ofrece un contraste a estas tendencias, partiendo del supuesto de que diferentes estrategias internacionales de integración generan marcos legales y políticas públicas de propiedad industrial significativamente diferentes. A partir de la comparación, se concluye que poseer mayor autonomía internacional permite generar leyes y políticas de la propiedad intelectual que se convierten en un instrumento para el desarrollo.

Palabras clave: propiedad industrial; políticas públicas; innovación y desarrollo; acuerdos internacionales 


\section{ABSTRACT}

Currently there is a double tendency regarding intellectual property. On the one hand, a turn from law to commercial logic, inasmuch as international intellectual property agreements are signed as "annexes" of international agreements and treaties, and not as autonomous legal agreements. On the other hand, a tendency towards the homogenization of intellectual property laws aimed towards a greater strictness in terms of protection periods and legal penalties. This without taking into account the differences between countries with different productive structures, and not assessing intellectual property in development processes. Based on the observation of the Brazil and Chile cases (international commercial agreements, industrial property laws and policies), we offer a contrast to these tendencies parting from the assumption that different international integration strategies generate significantly different legal frameworks and public policies on industrial property. Based on the comparison, we conclude that having greater international autonomy allows the generation of laws and policies on intellectual property that become an instrument for development.

Keywords: industrial property; public policies; innovation and development; international agreements

\section{SUMARIO}

Introducción.- I. Propiedad Intelectual y Comercio Internacional.- II. Propiedad intelectual, inNovación y desarrollo.- III. Metodología.IV. VÍAS DIVERGENTES DE INTEGRACIÓN INTERNACIONAL Y DE FORMULACIÓN DE LEYES Y POLÍTICAS DE PROPIEDAD INDUSTRIAL.- A. Acuerdos de propiedad intelectual administrados por OMPI.- B. Acuerdos multilaterales relacionados con propiedad intelectual.- C. Acuerdos regionales de propiedad intelectual.- D. Acuerdos bilaterales pertinentes a la propiedad intelectual.E. Utilización de mecanismos de diálogo y resolución de controversias.- $F$. Efectos sobre las leyes de propiedad industrial.- G. Efectos sobre las politicas públicas. - CONCLUSIONES: ORIENTADOS A UNA MAYOR AUTONOMÍA PARA POTENCIAR EL DESARROLLO.- BibLIOGRAFía. 


\section{INTRODUCCIÓN}

En las últimas décadas, se han producido profundos cambios en el ámbito de la propiedad intelectual ${ }^{1}$ referidos tanto a su integración en acuerdos comerciales transnacionales como la tendencia a la homogeneización mundial de las legislaciones sobre esta materia.

Como ha expresado Manuel Castells ${ }^{2}$, uno de los desafíos fundamentales de los estados en la actualidad es aprender a navegar la globalización, es decir, aprender a vincularse y establecer relaciones con otros países comprendiendo los efectos que esto trae sobre su gobernabilidad política y sus posibilidades de desarrollo. Uno de los ámbitos centrales de esta navegación es el de la propiedad intelectual (y de forma más específica, la propiedad industrial), que conjuga las necesidades de integración comercial y el incentivo a la innovación nacional y el desarrollo. Sin embargo, si no se toma en cuenta la necesidad de equilibrar integración comercial y desarrollo, la navegación nunca llegará a buen puerto.

El presente artículo compara las trayectorias de navegación de Brasil y Chile en el ámbito de la propiedad industrial, a partir de dos hipótesis que permiten comprender las divergencias de ambos casos respecto a leyes y políticas de propiedad industrial. En primer lugar, las diferencias legales entre ambos países se explican a partir de:

1. diferentes estrategias de integración comercial internacional;

2. diferentes valoraciones de la relevancia política de la propiedad industrial; $\mathrm{y}$

3. diferencias temporales en la promulgación de sus respectivas leyes de propiedad industrial.

En segundo lugar, las diferencias en las políticas de PI se explican a partir de:

1. diferentes estructuras productivas de los países;

1 Hay dos grandes ramas de la propiedad intelectual. En primer lugar, la vinculada con la autoría de obras intelectuales y que denominaremos derecho de autor; y en segundo lugar, aquella vinculada con la protección intelectual de diversos productos comerciales o industriales denominada genéricamente como propiedad industrial. En algunos casos, las legislaciones específicas de países difieren respecto a si un determinado tipo de protección debe incluirse en uno u otro grupo. Aunque este artículo se refiere más a cuestiones vinculadas con propiedad industrial, a veces se utilizará la expresión genérica "propiedad intelectual".

2 Manuel Castells, Globalización, desarrollo y democracia: Chile en el contexto mundial (Fondo de Cultura Económica, FCE, Santiago de Chile, 2005). 
2. nuevamente, diferentes valores políticos atribuidos a la propiedad industrial y la innovación; y

3. diferentes tiempos de implementación de políticas de propiedad industrial.

Este contraste evidencia que una mayor autonomía internacional (respecto a compromisos adquiridos en acuerdos comerciales internacionales) permite implementar leyes y políticas más coherentes con las necesidades de innovación y desarrollo nacionales. Por el contrario, una integración comercial internacional vinculante genera leyes y políticas dependientes del entorno global, y desvinculadas de las necesidades nacionales en el área.

En primer lugar, se presenta una discusión teórica respecto a la vinculación de las leyes de propiedad industrial con los acuerdos comerciales internacionales y con el incentivo de la innovación. En segundo lugar, se definen las estrategias metodológicas para efectuar la comparación entre ambos casos. Finalmente, se entregan los principales resultados de la comparación.

\section{PROPIEDAD INTELECTUAL Y COMERCIO INTERNACIONAL}

Las transformaciones en materia de leyes y políticas de propiedad intelectual (y de forma específica, de propiedad industrial) son determinadas por procesos globales de integración comercial todavía en curso. En este marco global de orientación se pueden destacar dos acuerdos claves conocidos como Acuerdos de Propiedad Intelectual vinculados con el Comercio (ADPIC) y ADPIC-plus.

En 1995, en el contexto de la creación de la Organización Mundial de Comercio (OMC) se firmó el ADPIC. Este acuerdo es el más relevante en la materia, debido a la amplitud de sus signatarios y a que pasó a convertirse en estándar mundial.

Con posterioridad, Estados Unidos, la Unión Europea y otros países desarrollados han efectuado acuerdos comerciales regionales en los que también definen exigencias en materia de propiedad intelectual más rigurosas que las de la $\mathrm{OMC}$, y que son conocidas como ADPIC-plus. Al comentar los anexos de propiedad intelectual 
del ALCA, Manuel Becerra-Ramírez ${ }^{3}$ y Benjamin Coriat ${ }^{4}$ sugieren que su intención es internacionalizar las leyes de propiedad intelectual estadounidenses.

Al escribir este artículo, el Acuerdo de Asociación Transpacífico - entre Australia, Brunei Darussalam, Canadá, Chile, Estados Unidos, Japón, Malasia, México, Nueva Zelandia, Perú, Singapur y Vietnam-está en plena negociación e incluye anexos de propiedad que implican un nuevo "plus" en relación con acuerdos previos.

ADPIC y ADPIC-plus son acuerdos vinculantes, lo que implica que los países signatarios se comprometen a realizar reformas en leyes y políticas públicas de propiedad intelectual e industrial. El no cumplimiento de los compromisos adquiridos implica que un país signatario sea llamado a consulta, y llegado el caso, se le impongan sanciones comerciales.

El efecto de estos acuerdos sobre el contenido de la propiedad industrial está ampliamente documentado. Como expresan Jacqueline Abarza y Jorge Katz ${ }^{5}$, Manuel Becerra-Ramírez, Benjamin Coriat, Félix Rozanski ${ }^{6}$, y Francisco Sercovich ${ }^{7}$, esto implica un mayor número de derechos de propiedad otorgados, una menor cantidad de límites y exclusiones para los propietarios; una ampliación en los tiempos de protección; la definición de nuevos objetos de conocimiento que pueden apropiarse; y una mayor rigurosidad en la definición de delitos y sanciones por violar la propiedad industrial.

Junto con ello, la armonización es un concepto ampliamente utilizado por diversas instancias internacionales para referirse a los objetivos de estos acuerdos de PI, tal como se muestra en esta presentación de los objetivos del Acuerdo sobre Derechos de Pa-

3 ManUel BeCERRA-RAmírez, La propiedad intelectual en transformación (Ediciones Universidad Nacional Autónoma de México, UNAM, México, 2004). Disponible en: http://biblio.juridicas. unam.mx/libros/libro.htm?1=1526

4 Benjamin Coriat, El régimen de la propiedad intelectual y la innovación, 233 Realidad Económica, 49-65 (2008).

5 Jacqueline Abarza \& Jorge Katz, Los derechos de propiedad intelectual en el mundo de la OMC (Naciones Unidas, Comisión Económica para América Latina y el Caribe, CEPAL, Santiago de Chile, 2002). Disponible en: http://portal.concytec.gob.pe/images/stories/images2012/portal/areas-institucion/dag/curso-politicas-ctei/propiedad-intelectual/1.pdf

6 Félix RozAnski, El valor de la propiedad intelectual en los paises en desarrollo, 28 Interciencia, 2, 105-110 (2003). Disponible en: http://www.interciencia.org/v28_02/rozanski

7 Francisco Sercovich, Tratados de libre comercio, derechos de propiedad intelectual y brecha de desarrollo: dimensiones de politica desde una perspectiva latinoamericana (Naciones Unidas, Comisión Económica para América Latina y el Caribe, CEPAL, México, 2008). Disponible en: http://repositorio.cepal.org/bitstream/handle/11362/4877/S0800444_es.pdf?sequence=1 
tentes (Patent Law Treaty, PLT) de la Organización Mundial de Propiedad Intelectual, OMPI:

El PLT tiene por fin armonizar las formalidades nacionales en materia de patentes en todo el mundo. (...) En 1995 se acordó que la OMPI adoptara otro planteamiento para promover la armonización, abarcando los asuntos relativos a los requisitos formales de los procedimientos nacionales y regionales sobre patentes ${ }^{8}$.

Sin embargo, como señala Ha-Joon Chang ${ }^{9}$, muchas de las instituciones en este proceso de armonización mundial son el resultado de la actualización institucional de los países desarrollados y no fruto de un consenso internacional; a la vez que para los países en desarrollo implican aumento en los costos de gestión institucional de la PI, y ser irrelevantes, o dañinas para sus propios objetivos de desarrollo.

En este sentido, Francisco Sercovich ${ }^{10}$ ha llegado a sugerir que, debido a la asimetría en los procesos de negociación y a sus consecuencias inciertas, los países latinoamericanos deberían abstenerse o detener negociaciones en curso referidas a propiedad intelectual hasta tener claridad respecto a las posibles desventajas que trae para los países en desarrollo, y en la medida en que no se comprenda el papel del conocimiento como generador actual y futuro de inequidades sociales y económicas entre las naciones. Un punto de vista similar puede encontrarse en varios autores, todos ellos vinculados con la Comisión Económica para América Latina y el Caribe, CEPAL, quienes coinciden en líneas generales en lo planteado por Francisco Sercovich, como Jorge Mario: Díaz ${ }^{11}$, Jorge Mario Martínez ${ }^{12}$, o Jacqueline Abarza y Jorge Katz.

8 Tratado sobre el Derecho de Patentes (PLT). Disponible en: http://www.wipo.int/patent-law/ es/plt.htm (visitado en: Nov. 16, 2011). Texto resaltado por el autor.

9 Ha-Joon Chang, Intellectual Property Rights and Economic Development. Historical Lessons and Emerging Issues, 2 Journal of Human Development, 2, 287-309 (2001).

10 Cfr. Francisco Sercovich, Tratados de libre comercio, derechos de propiedad intelectual y brecha de desarrollo: dimensiones de politica desde una perspectiva latinoamericana (Naciones Unidas, Comisión Económica para América Latina y el Caribe, CEPAL, México, 2008). Disponible en: http://repositorio.cepal.org/bitstream/handle/11362/4877/S0800444_es.pdf?sequence $=1$

11 Álvaro Díaz, América Latina y el Caribe: la propiedad intelectual después de los tratados de libre comercio (Naciones Unidas, Comisión Económica para América Latina y el Caribe, CEPAL, Santiago de Chile, 2008). Disponible en: http://repositorio.cepal.org/bitstream/ handle/11362/2526/S0600728_es.pdf?sequence $=1$

12 Jorge Mario Martínez-Piva, Capitulo II. La protección de los derechos de propiedad intelectual, la innovación y el desarrollo, en Generación y protección del conocimiento: propiedad intelectual, 


\section{PROPIEDAD INTELECTUAL, INNOVACIÓN Y DESARROLLO}

La función original de la propiedad industrial era proteger las diversas ventajas comparativas tanto de productores como de quienes generan innovaciones científicas y tecnológicas con valor de mercado. Hay empresas que han consolidado una imagen de marca sólida, otras cuentan con la garantía de calidad de zonas geográficas donde producen; otras, por su capacidad de generar innovación y nuevas tecnologías para el consumo, que protegen por medio de patentes, diseños industriales u otros mecanismos legales.

Las leyes y las políticas públicas de propiedad industrial deberían impulsarse, por tanto, en función de las estrategias de desarrollo de los países, es decir, desde el papel que desempeñan como parte de las políticas productivas, y de innovación y desarrollo; no exclusivamente desde la integración comercial internacional. En esta vinculación con los procesos productivos debe tenerse en cuenta una mirada de largo aliento, ya que resulta evidente la necesidad que tienen los países en desarrollo de generar transformaciones en sus estructuras productivas para aumentar su competitividad internacional y la propia sostenibilidad de sus economías en el futuro.

Esta transformación implica desarrollar e incorporar ciencia y tecnología a los procesos productivos; sin embargo, la mayoría de los países de la región latinoamericana están en deuda en este ámbito. Según señala el BID ${ }^{13}$, en el texto escrito por Gustavo Crespi, Juan Carlos Navarro y Pluvia Zúñiga (2010), la inversión en I+D de Brasil representa un 59\% de la región, en contraste con lo anterior, la de Chile llega solo a un 4\%. Por esto, este tipo de políticas es todavía un desafío pendiente que implica cambios profundos respecto al rol del Estado en la economía así como también de los diversos actores involucrados en su transformación y adaptación al nuevo

innovación y desarrollo económico, 59-90 (Jorge Mario Martínez-Piva, Naciones Unidas, Comisión Económica para América Latina y el Caribe, CEPAL, México, 2008). Disponible en: http://www.cepal.org/es/publicaciones/2873-generacion-y-proteccion-del-conocimientopropiedad-intelectual-innovacion-y

13 Banco Interamericano de Desarrollo, BID, Ciencia, tecnología e innovación en América Latina y el Caribe: un compendio estadístico de indicadores (Banco Interamericano de Desarrollo, New York, 2010). Disponible en: http://www.iadb.org/es/publicaciones/detalle,7101.html?id=67649 
contexto de la Economía del Conocimiento. Díaz sintetiza estos desafíos al proponer que se debe:

...incrementar sustancialmente los recursos destinados a la investigación científico-tecnológica, la innovación y la transferencia de tecnologías. Esto requiere estrategias nacionales de largo aliento, compuestas de etapas ofases, para poder avanzar en forma sostenida hacia sistemas de innovación de escala nacional, regional o ambas ${ }^{14}$.

Sin embargo, hay que situar esta discusión en las transformaciones que la propiedad industrial, y en especial las patentes, han experimentado por su creciente vinculación con cuestiones comerciales. Su intención original era asegurar la propiedad temporal de una forma de conocimiento; esto permite la difusión protegida de nuevo conocimiento; evita duplicidades en la investigación científica y tecnológica; y facilita, a su vez, la transabilidad en el mercado, es decir, la obtención de beneficios económicos para los innovadores, entendidas como incentivos para la innovación.

Pero en el contexto actual, según expresan Mario Cimoli y Annalisa Primi ${ }^{15}$, la tendencia muestra que las patentes se están convirtiendo en productos transables en el mercado. Esto implica que las necesidades de los países desarrollados y de grandes empresas transnacionales serían diferentes a las de los países en desarrollo por su vinculación y acceso a mercados científico-tecnológicos diferentes.

Por una parte, con diverso grado de éxito, los países en desarrollo estarían buscando ampliar su presencia en mercados de tecnología y mercados de ciencia, en los cuales el rol de las patentes está orientado a la protección, la difusión y la comercialización; y cuyos límites estarían vinculados con las capacidades tecnológicas y productivas (de países que habitualmente no producen tecnologías ni ciencia). Si los países y sus actores productivos innovan, su

14 Álvaro Díaz, América Latina y el Caribe: la propiedad intelectual después de los tratados de libre comercio, 207 (Naciones Unidas, Comisión Económica para América Latina y el Caribe, CEPAL, Santiago de Chile, 2008). Disponible en: http://repositorio.cepal.org/bitstream/ handle/11362/2526/S0600728_es.pdf?sequence $=1$

15 Mario Cimoli \& Annalisa Primi, Technology and Intellectual Property: A Taxonomy of Contemporary Markets for Knowledge and their Implications for Development (Naciones Unidas, Comisión Económica para América Latina y el Caribe, CEPAL, Santiago de Chile, 2007). Disponible en: http://citeseerx.ist.psu.edu/viewdoc/download?doi=10.1.1.121.5414\&rep=rep1\&type $=$ pdf 
importancia en estos mercados crece; sin embargo, están profundamente vinculados con el control que los países desarrollados y las grandes empresas transnacionales ejercen sobre los denominados mercados secundarios de ciencia y tecnología. En ellos, las patentes tienen un valor de mercado en sí mismas, más allá de la tecnología que protejan; y adquieren un valor como activos de las empresas, por lo cual cumplen diversas funciones estratégicas entre las que destacan las vinculadas a los mercados líquidos de conocimiento y que implican licencias cruzadas (dos o más empresas que controlan las patentes clave de un mercado específico), fusiones y adquisiciones (se compran o fusionan empresas para adquirir patentes clave en mercados controlados), y carteras de patentes (la capacidad de acción estratégica que permite el control de una gran cantidad de patentes).

Por otra parte, en los mercados derivados de conocimiento, las patentes son utilizadas como patentes durmientes (es decir, que se guardan hasta cuando tengan relevancia estratégica en un mercado); patentes de bloqueo (que protegen tecnologías clave para ingresar competitivamente a un mercado) y patentes defensivas (que son utilizadas como contramedidas cuando las empresas son atacadas por su uso de otras tecnologías).

Siguiendo a Mario Cimoli y Annalisa Primi, tanto en sus capacidades productivas internas como en el rol que los países en desarrollo juegan en los mercados internacionales de conocimiento, estos tienen capacidades limitadas de decodificar y producir innovaciones tecnológicas; tienen capacidades limitadas para producir ciencia con valor de mercado; y tienen nulas o muy limitadas capacidades estratégicas para intervenir en los mercados secundarios de ciencia y tecnología.

En un contexto mundial marcado por profundas diferencias en la producción de patentes y otras formas de protección entre países desarrollados y países en desarrollo, como lo muestran las estadísticas de propiedad intelectual de la $\mathrm{OMPI}^{16}$ o la $\mathrm{OCDE}^{17}$, de

16 Organización Mundial de Propiedad Intelectual, OMPI, World Intellectual Property Indicators (2013). Disponible en: http://www.wipo.int/ipstats/en/wipi/

17 Organización para la Cooperación y el Desarrollo Económicos, OCDE, Chile lidera América Latina y supera a 10 países $O C D E$ en ranking mundial de Sociedad de la Información. Disponible en: http://www.subtel.gob.cl/chile-lidera-america-latina-y-supera-a-10-paisesocde-en-ranking-mundial-de-sociedad-de-la-informacion/, http://www.subtel.gob.cl/ 
nuevo, es relevante preguntarse por las asimetrías de los acuerdos comerciales, la inclusión de anexos de propiedad industrial en ellos y las capacidades de negociación de los países.

\section{METODOLOGÍA}

La investigación realizada implicó una comparación entre Brasil y Chile que, siendo dos de las economías más dinámicas de la región, poseen diferencias significativas por su peso económico y geoestratégico. En este sentido, como señalan Giovanni Sartori y Leonardo Morlino ${ }^{18}$, y David Marsh y Gerry Stoker ${ }^{19}$, son entendidos como casos extremos en los cuales la constante que permite la comparación estaría vinculada con la propiedad industrial observada en dos dimensiones de complejidad estructural: el ámbito internacional de los acuerdos de propiedad industrial; y el ámbito nacional de las leyes y políticas públicas en la materia.

Respecto a la dimensión internacional, la observación se concentró en determinar qué acuerdos ha firmado cada país, considerando también factores temporales y las circunstancias que influyeron en la toma de decisiones.

Las categorías de observación para esta dimensión se definieron a partir de la tipología propuesta por la Organización Mundial de Propiedad Intelectual ${ }^{20}$ que los agrupa de la siguiente forma: 1) administrados por la OMPI (25 en total); 2) Multilaterales relacionados con propiedad intelectual (59 en total); 3) acuerdos regionales de propiedad intelectual ( 3 en total); y 4 ) bilaterales y multilaterales pertinentes a la propiedad intelectual (9 en total).

Adicionalmente, se observó la utilización de los mecanismos de diálogo y resolución de controversias que aportan los acuerdos internacionales, siendo el único relevante el vinculado con las Diferencias respecto a los Acuerdos ADPIC en el ámbito de la OMC,

index.php?option $=$ com_content $\&$ view $=$ article $\&$ id $=3197 \% 3$ Achile-lidera-america-latina-ysupera-a-10-paises-ocde-en-ranking-mundial-de-sociedad-de-la-informacion- $\&$ catid $=95 \% 3$ Aservicios-telecomunicaciones\&Itemid=786\&lang=es

18 Giovanni Sartori \& Leonardo Morlino (eds.), La comparación en las ciencias sociales (Alianza Editorial, Madrid, 1996).

19 David Marsh \& Gerry StoKer, Theory and Methods in Political Science (Palgrave MacMillan, New York, 1995).

20 Organización Mundial de la Propiedad Intelectual, OMPI, WIPO Lex. Disponible en: http:// www.wipo.int/wipolex/es/ 
ya que los mecanismos de resolución de controversias de la OMPI no arrojan datos significativos para ambos países. La observación se efectuó a partir de un análisis de contenido de diversos documentos, como bases de datos de la OMC, la OMPI y de los gobiernos de ambos países.

La dimensión nacional se orientó a observar las diferencias y semejanzas en los marcos legales de propiedad industrial de ambos países, con un análisis de contenido de las legislaciones a partir de la presencia o ausencia de las siguientes características: 1) nuevos derechos otorgados; 2) límites y exclusiones legales; 3) mayores tiempos de protección; 4) nuevos objetos de protección; y 5) tipificación de delitos y sanciones, y evaluaciones de la rigurosidad de las leyes.

Finalmente, la comparación en políticas públicas de propiedad industrial. Para ello se desarrollaron tres categorías de análisis orientadas a observar posibles transformaciones en el abordaje político institucional de la propiedad industrial, y en los discursos que justifican estos procesos de cambio. 1) La presencia de la propiedad intelectual en el aparato institucional de los gobiernos; 2) la modernización o los cambios de los respectivos institutos de propiedad industrial; y 3) las funciones asumidas por esos institutos. En el caso chileno se efectuó una entrevista con personal del Instituto Nacional de Propiedad Industrial, INAPI. En ambos casos, la información fue recopilada en el período 2008-2011. Cuando resultó pertinente, se hizo un seguimiento de los casos hasta 2014.

\section{VÍAS DIVERGENTES DE INTEGRACIÓN INTERNACIONAL Y DE FORMULACIÓN DE LEYES Y POLÍTICAS DE PROPIEDAD INDUSTRIAL}

El número de acuerdos internacionales que se relacionan directa o indirectamente con la propiedad industrial es muy amplio y diverso. Brasil firmó desde finales del siglo XIX hasta finales del siglo XX cincuenta y un acuerdos (ninguno con posterioridad al año 2000). Chile ha firmado cincuenta y ocho en un período un poco más amplio. Sin embargo, estos números tienen significativas diferencias de contenido. 


\section{A. Acuerdos de propiedad intelectual administrados por OMPI}

De los 25 acuerdos OMPI, Brasil ha firmado ocho y Chile, doce. Muchos de los tratados firmados son idénticos (7 en total); sin embargo, lo que establece la diferencia observable más significativa es la fecha en que entraron en vigor. En Brasil no se ha firmado ninguno de ellos con posterioridad a 1992, lo que contrasta significativamente con Chile, pues seis de ellos entraron en vigor ya en el siglo XXI.

No es lo mismo firmar el Tratado de Cooperación en Materia de Patentes (PCT) en 1978, como ocurrió con Brasil, que hacerlo treinta y un años después, en 2009, como sucedió en Chile. Esta tendencia muestra que la firma de los tratados en Chile es reactiva y como veremos más adelante, surge de la exigencia planteada por otros acuerdos internacionales de concentrarse fundamentalmente en materias de alta tecnología, como obtenciones vegetales, material genético y nuevas tecnológicas asociadas al derecho de autor y las marcas.

\section{B. Acuerdos multilaterales relacionados con propiedad intelectual}

Los acuerdos de este tipo abarcan un amplio número de países y materias. A modo de ejemplo, pueden mencionarse temas como diversidad biológica, discapacidad, comunicaciones internacionales, acuerdos educativos, etcétera. La OMPI indica que son cincuenta y nueve en total.

Brasil ha firmado o tiene en vigor treinta y siete y Chile treinta y cuatro, ambos países en períodos comparables, siendo relevante mencionar que en este grupo se encuentra el ya mencionado TRIPS (trade-related aspects of intellectual property rights, en vigor en ambos países desde 1995). La diferencia más relevante es la referida al Convenio Internacional para la Protección de las Obtenciones Vegetales (UPOV) ${ }^{21}$, que entró en vigor en Brasil en 1999, pero que

21 Unión Internacional para la Protección de las Obtenciones Vegetales, UPOV, Convenio Internacional para la Protección de las Obtenciones Vegetales, adoptado por una Conferencia Diplomática, el 2 de diciembre de 1961, en París. Disponible en: http://www.upov.int/upovlex/ es/upov_convention.html 
solo ha sido firmado por Chile aunque no ratificado, ya que desde el año 2009 se está discutiendo su aprobación en el Congreso ${ }^{22}$.

\section{Acuerdos regionales de propiedad intelectual}

El tercer grupo son los tratados regionales de PI, es decir, aquellos acuerdos exclusivos entre países americanos. Llama la atención la poca importancia concedida al tema, que pone de manifiesto una profunda falta de interés por la regulación y protección del conocimiento científico técnico entre los países de la región, y su falta de aplicación en procesos industriales o respecto al desarrollo de innovaciones tecnológicas.

Según la OMPI, en Latinoamérica, solo hay tres acuerdos referidos a PI, todos ellos administrados por la Organización de Estados Americanos, OEA. La Convención General Interamericana sobre Protección Marcaria y Comercial ${ }^{23}$, que fue firmada (pero no ratificada) por ambos países en 1929. La Convención Interamericana sobre el Derecho de Autor en Obras Literarias, Científicas y Artísticas $^{24}$, que entró en vigor en Brasil en 1949 y en Chile en 1955; y el Protocolo sobre Uniformidad del Régimen Legal de los Poderes ${ }^{25}$, referido a Propiedad Industrial, que entró en vigor únicamente en Brasil en 1941, sin que Chile se haya integrado.

¿Puede interpretarse esto como un reflejo del estancamiento tecnológico de esta región latinoamericana? Esta falta de preocupación por el tema en las relaciones entre los países de la región refleja que la propiedad industrial no ha sido relevante en relación con procesos de intercambio comercial y tecnológico entre países latinoamericanos (es decir, sin acuerdos simétricos), y muestra que la integración a acuerdos internacionales ha sido más bien entre países desarrollados-subdesarrollados, con el control tecnológico y de las

22 Senado de Chile, Boletín 6355-01. Disponible en: http://www.senado.cl/appsenado/templates/ tramitacion/index.php\#

23 Convención General Interamericana sobre Protección Marcaria y Comercial, 20 de febrero de 1929, Washington. Disponible en: http://www.wipo.int/wipolex/es/details.jsp?id=12625

24 Convención Interamericana sobre el Derecho de Autor en Obras Literarias, Científicas y Artísticas, 22 de junio de 1946, Washington. Disponible en: http://www.wipo.int/wipolex/es/ other_treaties/details.jsp?group_id=21\&treaty_id $=378$

25 Protocolo sobre Uniformidad del Régimen Legal de los Poderes, 17 de febrero de 1940, Washington. Disponible en: http://www.wipo.int/wipolex/es/other_treaties/details.jsp?group_ id=22\&treaty_id=389 
relaciones comerciales dispares que esto trae consigo, acentuadas aún más en el contexto actual de la sociedad del conocimiento.

\section{Acuerdos bilaterales pertinentes a la propiedad intelectual}

Los tratados bilaterales pertinentes a la propiedad industrial marcan diferencias sustanciales entre ambos países. Como Brasil ha privilegiado efectuar su proceso de integración comercial internacional por medio del Mercado Común del Sur, MERCOSUR, es decir, en conjunto con Argentina, Uruguay, Paraguay (y con Venezuela y Bolivia, hasta ese momento, en proceso de incorporación), no recibe exigencias directas de otros países en materia de PI.

Chile, en cambio, es el país que más acuerdos bilaterales comerciales ha firmado en el mundo (27 en total, ya sea en vigor o en negociación). Nueve de ellos son considerados por la OMPI como relevantes en materia de PI, de los cuales cinco fueron con países o grupos de países desarrollados ${ }^{26}$. Entre ellos destacan el Acuerdo Interino entre la Comunidad Europea y Chile (en vigor desde $2003^{27}$ ), y el Tratado de Libre Comercio entre Estados Unidos y Chile (en vigor desde $2004^{28}$ ); estos son los que anteriormente identificamos como "ADPIC-plus", con los que se busca, por una parte ampliar la exigencia legal (más sanciones y condenas más amplias); y por otro lado, ampliar los objetos de protección (de forma indirecta: al generar protecciones administrativas o regular el secreto industrial; o de forma directa: al ampliar plazos de protección o crear formas de protección nuevas en ámbitos como la genética, el procesamiento computacional, entre otros). En el futuro, habrá que considerar el impacto adicional del Acuerdo Transpacífico todavía en negociación ${ }^{29}$.

26 Se señalaba en los párrafos anteriores que la propiedad industrial no ha sido relevante entre los países de la región; sin embargo, en el contexto de su vinculación con tratados bilaterales de índole comercial Chile ha firmado anexos sobre diversos aspectos del tema con Panamá (2008), Costa Rica (2002), El Salvador (2002) y México (1999). El denominador común en ellos es el piso mínimo establecido por la OMC por medio del ADPIC.

27 Acuerdo Interino entre la Comunidad Europea y Chile, 18 de noviembre de 2002, Bruselas. Disponible en: http://www.wipo.int/edocs/lexdocs/treaties/es/cl-ec/trt_cl_ec.pdf

28 Tratado de Libre Comercio entre Estados Unidos y Chile, 6 de junio de 2003. Disponible en: http://www.direcon.gob.cl/detalle-de-acuerdos/?idacuerdo=6277

29 Gobierno de Chile, Dirección General de Relaciones Económicas Internacionales, Acuerdos comerciales. Disponible en: http://www.direcon.gob.cl/acuerdos-comerciales/ 
Una de las repercusiones concretas de estos dos acuerdos es lo que se describía al inicio de esta sección. De los doce acuerdos administrados por la OMPI que están en vigor en Chile, la mitad ocurrió en el período 2000-2011, en el contexto de negociación, entrada en vigencia y compromisos asumidos en los acuerdos bilaterales con Estados Unidos y la Unión Europea. Respecto al primero, se pide la adhesión y ratificación de ocho acuerdos, siendo el más complejo el de la Unión Internacional para la Protección de Obtenciones Vegetales (UPOV), en trámite en el Senado de Chile, pero que no han sido aprobadas por una petición de inconstitucionalidad. En el caso de la Unión Europea se exigía la firma de nueve tratados de los que están pendientes dos y otro que ya había sido firmado con anterioridad en 1977.

En este contexto también en 2007 y 2010 se aprueban en Chile nuevas leyes de propiedad industrial y de propiedad intelectual (referida en realidad al derecho de autor). En estas leyes se agregan nuevos y más amplios plazos de protección y los mecanismos adicionales, como protección de información no divulgada en los ámbitos farmacéuticos y químico-agrícolas. La documentación disponible ${ }^{30}$ permite señalar que la modernización de los cuerpos legales se origina en la necesidad de cumplir las obligaciones internacionales y, en especial, respecto a los procesos, en ese momento en curso, de negociación de acuerdos comerciales con la Unión Europea y Estados Unidos. En el registro de la discusión parlamentaria, por ejemplo, se destaca la presentación de un diputado chileno quien señala: "Quiero destacar la importancia de esta iniciativa, que es previa a la firma de tratados tan importantes como los de Libre Comercio con Estados Unidos y la Unión Europea"31.

Por otra parte, en ambos acuerdos se establecen mecanismos de cooperación, que en la práctica han operado más bien de forma unilateral. Estados Unidos ofrece educación y difusión de PI en ámbitos de investigación e innovación, y respecto a la observancia de las leyes. Para la Unión Europea, la cooperación consiste en ase-

30 Biblioteca del Congreso Nacional de Chile, Historia de la Ley No 19.996. Modifica la Ley No 19.039 sobre propiedad intelectual. Disponible en: http://www.leychile.cl/Navegar/scripts/ obtienearchivo?id=recursoslegales/10221.3/4216/1/HL19996.pdf

31 Biblioteca del Congreso Nacional de Chile, Historia de la Ley No 19.996. Modifica la Ley No 19.039 sobre propiedad intelectual. Disponible en: http://www.leychile.cl/Navegar/scripts/ obtienearchivo?id=recursoslegales/10221.3/4216/1/HL19996.pdf 
sorías legislativas y de la organización administrativa de la PI con un claro impacto en política pública, así como también formación para jueces, y funcionarios de aduanas y policía. Las adaptaciones en los cuerpos legales han sido también unilaterales, ya que solo Chile ha modificado sus leyes y políticas, no así Estados Unidos o la Unión Europea.

Puede apreciarse que, en materia de PI, estos acuerdos están marcados por profundas asimetrías. Las exigencias vienen dadas desde los países desarrollados, en este caso hacia Chile, que debe adaptarse a este nuevo entorno no desde su propio proceso de búsqueda del desarrollo mediante la innovación y la protección del conocimiento generado, sino orientado por la necesidad de integración comercial.

\section{E. Utilización de mecanismos de diálogo y resolución de controversias}

Otra dimensión relevante de los cambios en materia de PI producto de su creciente integración a los acuerdos de libre comercio, es que adquieren carácter vinculante, es decir, generan obligaciones internacionales, que si no se cumplen, podrían derivar en sanciones comerciales. En esta categoría de análisis es posible apreciar con mayor claridad el peso estratégico internacional de Brasil y la utilización de la propiedad industrial como mecanismo de presión política y económica.

Se buscaba establecer una comparación respecto a si Brasil o Chile habían utilizado estos mecanismos internacionales vinculantes o si se habían fijado reclamaciones contra ellos por supuestas vulneraciones a la propiedad industrial. Debido a la asimetría en cuanto a los acuerdos firmados por Brasil y Chile, la mejor opción para compararlos era observar su eventual involucramiento en las reclamaciones de la OMC referidas a PI.

Desde su creación en 1994, estos mecanismos se han utilizado solo en 29 ocasiones en tota ${ }^{32}$. Brasil está involucrado en dos casos

32 Hasta 2011, la mayor parte de reclamaciones proviene de países desarrollados (un 89,5\%), siendo Estados Unidos el que más ha presentado (17), seguido de la Unión Europea (7), Canadá (1) y Australia (1). Además de Brasil, el único país no desarrollado que ha presentado reclamaciones es India (1). Llama la atención también que muchas veces las reclamaciones son entre países desarrollados, aunque preferentemente en contra de países en vías de desarrollo. 
como reclamante, además de otro caso en que se solicitan medidas en su contra. Chile, en cambio, no ha participado bajo ninguna circunstancia en estos procesos ${ }^{33}$.

Las reclamaciones de y en contra de Brasil aportan datos significativos respecto al proceso de conducción política en sus posturas internacionales sobre PI. En 2001, Brasil presentó un llamado a consulta contra Estados Unidos por considerar que este país incurría en prácticas discriminatorias que afectaban el libre comercio, en la medida en que se impedía la fabricación de medicamentos fuera de Estados Unidos, si alguna patente involucrada en el producto se había inventado con ayuda federal en el país ${ }^{34}$. Como contramedida, Estados Unidos llama a consulta a Brasil por una disposición similar que exigía la "explotación local" de invenciones para evitar la pérdida del disfrute exclusivo de derechos, lo que desde la perspectiva estadounidense también afectaba el libre comercio ${ }^{35}$.

En 2010, Brasil presenta otra demanda; en esta ocasión, contra los Países Bajos y la Unión Europea, por impedir las relaciones comerciales entre India y Brasil al confiscar medicamentos en tránsito entre ambos países, que pasaron por puertos y aeropuertos europeos $^{36}$.

Los dos primeros casos entre Estados Unidos y Brasil se explican por una lógica de protección de los mercados internos, ya que ambos países intentaban mantener mecanismos adicionales de protección para impedir la producción de tecnologías nacionales fuera del país o para forzar la explotación de patentes por medio de licencias obligatorias. Estados Unidos busca proteger una posición de mercado privilegiada para evitar que se produzca tecnología propia fuera del país. Brasil, por otra parte, busca una mayor incorporación de tecnología en el país al regular que las patentes no queden "dormidas" 37 , es decir, sin explotar en el país.

33 Organización Mundial de Comercio, OMC, Solución de diferencias: las diferencias. Índice de diferencias por Acuerdo. Disponible en: http://www.wto.org/spanish/tratop_s/dispu_s/ dispu_agreements_index_s.htm?id=A26\#selected_agreement

34 Organización Mundial de Comercio, OMC, Solución de diferencias: las diferencias. DS224. Disponible en: http://www.wto.org/spanish/tratop_s/dispu_s/cases_s/ds224_s.htm

35 Organización Mundial de Comercio, OMC, Solución de diferencias: las diferencias. DS199. Disponible en: http://www.wto.org/spanish/tratop_s/dispu_s/cases_s/ds199_s.htm

36 Organización Mundial de Comercio, OMC, Solución de diferencias: las diferencias. DS409. Disponible en: http://www.wto.org/spanish/tratop_s/dispu_s/cases_s/ds409_s.htm

37 Como se señaló previamente, esto implica que una patente esté "dormida", sin utilizarse, a la espera de un mejor momento estratégico para obtener beneficios económicos. 
El tercer caso se vincula con la producción de medicamentos genéricos. Como veremos, Brasil ha señalado que los derechos de propiedad industrial no pueden estar por encima del derecho a la vida humana, y como la OMC garantiza la obligatoriedad de licencias en casos de extrema necesidad social, el país ha utilizado esto para adquirir a menor costo medicamentos genéricos para el tratamiento del SIDA en India. En este contexto, los medicamentos en tránsito han sido retenidos por vulnerar patentes farmacéuticas en un caso en que se siguen celebrando consultas en las instancias pertinentes de ADPIC. Por su parte, la demanda de Brasil e India hacia Holanda y la Unión Europea señalan que la medida de retención afecta el libre comercio entre los dos países.

Otra interesante controversia en la OMC es la del "Caso del Algodón" 38 . Brasil presentó en 2002 una reclamación contra Estados Unidos por aplicar subvenciones contracíclicas a los productores de algodón de su país, lo que afectaba a los productores de países subdesarrollados y también el mercado del algodón mundial ${ }^{39}$.

Para 2005, Estados Unidos no había dado una respuesta, y Brasil solicitó a la OMC la autorización para establecer sanciones comerciales, lo que el organismo internacional concedió por un monto de 829 millones de dólares anuales. Las sanciones se dividieron en 591 millones destinados a ciento dos productos (102, entre ellos el algodón), y los restantes 238 millones se aplicarían al mercado de servicios y PI, en especial software y patentes farmacéuticas, agroquímicas y biotecnológicas, lo que tuvo repercusiones negativas sobre la producción estadounidense de estas industrias ${ }^{40}$.

Aunque la OMC autorizó estas sanciones, finalmente nunca se llevaron a la práctica ya que Estados Unidos inició en ese momento negociaciones con Brasil, lo que llevó a que en 2012 se modificaran las legislaciones referidas a los subsidios, y que en octubre de 2014,

38 International Center for Trade and Sustainable Development, ICTSD, Brasil: OMC reafirma victoria en caso del algodón contra los EE.UU. Disponible en: http://ictsd.org/i/news/ puentesquincenal/10188/

39 Organización Mundial de Comercio, OMC, Estados Unidos - Subvenciones al algodón americano (Upland). Disponible en: http://www.wto.org/spanish/tratop_s/dispu_s/cases_s/ds267_s.htm

40 International Center for Trade and Sustainable Development, ICTSD, Brasil: OMC reafirma victoria en caso del algodón contra los EE.UU. Disponible en: http://ictsd.org/i/news/ puentesquincenal/10188/ 
ambos países acordaran un memorándum de entendimiento dando por finalizada la diferencia ${ }^{41}$.

En este contexto, Brasil se acerca a la propiedad industrial desde los límites que establece el interés público, como el derecho a la salud, y desde la preocupación de las necesidades de innovación y desarrollo nacionales, para establecer límites a su utilización como mecanismo de integración comercial.

En la Declaración Introductoria del Examen de Legislación que todos los miembros de ADPIC efectuaron para señalar el estado de sus leyes de PI y la necesidad de establecer modificaciones futuras, Brasil señalaba que:

...el Brasil no considera la protección de los derechos de propiedad intelectual como un fin en sí misma. Desde el punto de vista del Brasil, el ejercicio de los derechos de propiedad intelectual por sus titulares solo tiene sentido si es favorable a las políticas generales de interés público ${ }^{42}$.

Más adelante, destaca la declaración ministerial de Doha ${ }^{43}$ por situar por sobre la PI los derechos a la salud. El Gobierno de Brasil había expresado esta preocupación previamente a la OMC, al indicar:

...creemos que todavía puede ser necesario aclarar - y, cuando proceda, modificar - las disposiciones del Acuerdo para evitar una situación en la que las ambigüedades existentes o su interpretación puedan tener un efecto negativo en esferas como la salud, la transferencia de tecnología, el medio ambiente, la nutrición u otras necesidades de desarrollo ${ }^{44}$.

En contraste con esta postura, en el Examen de la Legislación ante el Consejo de los ADPIC de Chile, solo se menciona la nece-

41 Organización Mundial de Comercio, OMC, Estados Unidos - Subvenciones al algodón americano (Upland). Disponible en: http://www.wto.org/spanish/tratop_s/dispu_s/cases_s/ds267_s.htm

42 Gobierno de Brasil - Organización Mundial del Comercio, OMC, Examen de la legislación. Brasil (Organización Mundial del Comercio, OMC, 2004). Disponible en: https://docs.wto.org/ dol2fe/Pages/FE_Search/FE_S_S006.aspx?Query=@Symbol=\%20ip/q*\%20and\%20\%20@ Symbol $=\% 20 \mathrm{bra} \&$ Language $=$ SPANISH\&Context $=$ FomerScriptedSearch\&languageUICha nged=true\#

43 Organización Mundial de Comercio, OMC, Declaración relativa al Acuerdo sobre los ADPIC y la salud pública. Disponible en: http://www.wto.org/spanish/thewto_s/minist_s/min01_s/ mindecl_trips_s.htm

44 Gobierno de Brasil - Organización Mundial del Comercio, OMC, Examen de la legislación. Brasil (Organización Mundial del Comercio, OMC, 2004). Disponible en: https://docs.wto.org/ dol2fe/Pages/FE_Search/FE_S_S006.aspx?Query=@Symbol=\%20ip/q*\%20and\%20\%20@ 
sidad de adaptar las legislaciones nacionales y establecer nuevas leyes, no habiendo ninguna referencia a temas como el vínculo de la PI con la innovación y el desarrollo o resguardos respecto a los derechos de la salud. El único interés manifiesto es, por tanto, el de la integración comercial, cuando se señala:

...la aprobación de los Acuerdos de Marrakech significaron [sic] para nuestro país la necesidad de adoptar reformas legales tendientes a adecuar la legislación interna a las disposiciones de dichos Acuerdos. El área de la propiedad intelectual no estuvo ajena a esta necesidad. La reforma en Chile ha supuesto no solo modificar disposiciones preexistentes, sino que también introducir nuevas regulaciones, especialmente en ciertas categorías especificas de derechos, en las cuales no existía una normativa anterior ${ }^{45}$.

En la medida en que Brasil ha negociado su integración por medio del MERCOSUR, ha evitado ser sometido a presiones internacionales en materia de propiedad industrial, y por tanto, ha efectuado cambios en política pública, para responder a sus propias necesidades de innovación y desarrollo.

En cambio, en la última década, Chile ha firmado una serie de acuerdos comerciales que lo incentivan a modificar sustancialmente su integración a acuerdos de PI, que a la vez traen consecuencias que se hacen cada vez más evidentes en las políticas públicas del área. Estas divergencias internacionales se prolongan también al ámbito de las leyes y las políticas públicas de propiedad industrial.

\section{F. Efectos sobre las leyes de propiedad industrial}

La comparación de las legislaciones de Brasil y Chile se concentró en el análisis de la ley brasileña 9.279 de 1996; y de la ley chilena 19.039 de 2012; ambas referidas a la propiedad industrial. La más reciente modificación legal en Brasil se corresponde con el ingreso al ADPIC de la OMC; para el caso de Chile, el cambio más reciente se corresponde con las exigencias de los mencionados tratados con

Symbol $=\% 20$ bra $\&$ Language $=$ SPANISH $\&$ Context $=$ FomerScriptedSearch $\&$ languageUICha nged=true\#

45 Gobierno de Chile - Organización Mundial del Comercio, OMC, Examen de legislación. Chile (Organización Mundial del Comercio, OMC, 2001). Disponible en: https://docs.wto.org/ dol2fe/Pages/FE_Search/FE_S_S006.aspx?Query=@Symbol=\%20ip/q*\%20and\%20\%20@ Symbol $=\% 20$ ch $1 \&$ Language $=$ SPANISH $\&$ Context $=$ FomerScriptedSearch $\&$ languageUICha nged=true\# 
Estados Unidos y la Unión Europea, y en especial, por la adaptación de la ley para cumplir las exigencias del Tratado de Cooperación en materia de Patentes (TCP).

Un primer asunto a determinar es si la ley chilena presenta un mayor número de derechos otorgados que la legislación de Brasil. Esto es así en dos materias: marcas y secreto industrial. En relación con el primer tema, en Chile es posible utilizar como marcas nombres propios de personas y nombres de personajes históricos ${ }^{46}$; estas posibilidades no están definidas en la legislación brasileña ${ }^{47}$.

Por otra parte, la legislación chilena otorga derechos vinculados al secreto industrial (art. 86-88), que no son mecanismos directos de propiedad industrial, pero que sí son utilizados como mecanismos adicionales de protección ${ }^{48}$; en el caso de Brasil, el secreto industrial no aparece como tal en la mencionada ley, aunque se lo menciona de forma restringida respecto a su resguardo en los procesos de inscripción de una patente ${ }^{49}$, en procesos judiciales ${ }^{50}$; así como también en relación a cuestiones de seguridad nacional.

Un segundo asunto es la presencia de límites y exclusiones, es decir, que la ley establezca circunstancias en que los derechos de los titulares de una propiedad queden excluidos o limitados en sus beneficios. Acá se esperaba encontrar que la legislación brasileña presentará un mayor número de límites y exclusiones a la protección, lo que se hace especialmente evidente en el ámbito de las patentes; ya que la legislación permite que terceros utilicen productos patentados en diversos procesos que no les acarreen perjuicios económicos a los titulares ${ }^{51}$, como experimentos e investigaciones

46 Gobierno de Chile, Ley 19.039 sobre propiedad industrial (texto refundido, coordinado y sistematizado aprobado por el Decreto Ley 3), art. 20-c (2012). Disponible en: http://www. wipo.int/wipolex/es/text.jsp?file_id=175347

47 Gobierno de Brasil, Ley 9.279 de 14 de mayo de 1996. Regula derechos y obligaciones relativos a la propiedad industrial, art. 129-132. Disponible en: http://www.wipo.int/wipolex/es/details. jsp?id $=515$

48 Gobierno de Chile, Ley 19.039 sobre propiedad industrial (texto refundido, coordinado y sistematizado aprobado por el Decreto Ley 3) art. 86-89 (2012). Disponible en: http://www. wipo.int/wipolex/es/text.jsp?file_id=175347

49 Gobierno de Brasil, Ley 9.279 de 14 de mayo de 1996. Regula derechos y obligaciones relativos a la propiedad industrial, art. 30. Disponible en: http://www.wipo.int/wipolex/es/details. jsp?id $=515$

50 Gobierno de Brasil, Ley 9.279 de 14 de mayo de 1996. Regula derechos y obligaciones relativos a la propiedad industrial, art. 206. Disponible en: http://www.wipo.int/wipolex/es/details. jsp?id=515

51 Gobierno de Brasil, Ley 9.279 de 14 de mayo de 1996. Regula derechos y obligaciones relativos a la propiedad industrial, art. 43. Disponible en: http://www.wipo.int/wipolex/es/details.jsp?id=515 
científico-tecnológicas, o medicamentos preparados según prescripción médica. Llama la atención la posibilidad de utilizar productos para generar variantes (de una semilla, por ejemplo), ya que en este caso, el resultado puede tener repercusiones económicas ${ }^{52}$.

Otro tema relevante en este punto es lo que la legislación denomina "usuario anterior" 53 ; esto implica que si una persona o institución de buena fe utilizaba un producto patentado sin saberlo, puede seguir haciéndolo sin pagar gravámenes. Hay toda una sección de la ley dedicada a las denominadas licencias compulsorias ${ }^{54}$ que reconoce tres tipos de ellas: relacionadas con el uso abusivo de derechos de sus titulares, la no explotación en el país y las patentes dependientes (cuando la explotación de una patente requiere la utilización de otra). Estas pueden ser solicitadas por cualquier persona interesada y, adicionalmente, el poder federal puede solicitar licencias compulsorias en caso de emergencia o interés público nacional ${ }^{55}$. En una legislación posterior, se establecen mecanismos similares a las licencias compulsivas para las topografías de circuitos integrados ${ }^{56}$. El proceso para ver estas causas es administrativo (en el Instituto Nacional de Propiedad Industrial, INPI), no judicial.

Finalmente, se restringen los derechos de los titulares, cuando un invento desarrollado en el país puede afectar la defensa nacional ${ }^{57}$. Esto genera también prohibiciones de patentar productos derivados de la investigación del núcleo atómico, o la protección de seres vivos (aunque sí se permite la protección de microorganismo transgénicos $\left.{ }^{58}\right)$.

52 Gobierno de Brasil, Ley 9.279 de 14 de mayo de 1996. Regula derechos y obligaciones relativos a la propiedad industrial, art. 43, III. Disponible en: http://www.wipo.int/wipolex/es/details. jsp?id $=515$

53 Gobierno de Brasil, Ley 9.279 de 14 de mayo de 1996. Regula derechos y obligaciones relativos a la propiedad industrial, art. 45. Disponible en: http://www.wipo.int/wipolex/es/details. jsp?id $=515$

54 Gobierno de Brasil, Ley 9.279 de 14 de mayo de 1996. Regula derechos y obligaciones relativos a la propiedad industrial, art. 68-70. Disponible en: http://www.wipo.int/wipolex/es/details. jsp?id=515

55 Gobierno de Brasil, Ley 9.279 de 14 de mayo de 1996. Regula derechos y obligaciones relativos a la propiedad industrial, art. 71. Disponible en: http://www.wipo.int/wipolex/es/details. jsp?id $=515$

56 Gobierno de Brasil, Ley 11.484 del 31 de mayo de 2007 (topografías de circuitos integrados). Disponible en: http://www.wipo.int/wipolex/es/details.jsp?id=8307

57 Gobierno de Brasil, Ley 9.279 de 14 de mayo de 1996. Regula derechos y obligaciones relativos a la propiedad industrial, art. 75. Disponible en: http://www.wipo.int/wipolex/es/details. jsp?id $=515$

58 Gobierno de Brasil, Ley 9.279 de 14 de mayo de 1996. Regula derechos y obligaciones relati- 
El reconocimiento de límites y restricciones en la ley chilena es mucho más acotado. Se reconocen las restricciones vinculadas a no patentar seres vivos, métodos matemáticos o aquello que afecte la seguridad del Estado ${ }^{59}$. Las denominadas licencias no voluntarias (compulsorias) se restringen a permitir la libre competencia ${ }^{60}$, salud pública y seguridad naciona ${ }^{61}$ y en el caso de patentes dependientes. En el caso de Chile, estos procedimientos se resuelven por vía judicial. Debido a la importancia económica de la industria vitivinícola en el país, se establecen restricciones a la protección de origen de cepas de vinos, así como al pisco, denominación en disputa con Perú ${ }^{62}$. Como se vio anteriormente, es relevante señalar que Brasil ha utilizado las licencias compulsivas con fines públicos y de seguridad nacional, algo que no ha ocurrido en Chile.

El tercer ámbito de observación es el de los tiempos de protección, pues se esperaba que la legislación chilena considerara plazos más prolongados, ya sea por mecanismos directos (el tiempo establecido en la ley), como por mecanismos indirectos (es decir, procedimientos administrativos que prolongan el tiempo de protección). Efectivamente, y en especial, las diferencias respecto a las patentes son notorias.

En la ley brasileña, aunque se reconoce un plazo de protección de 20 años, adicionalmente se considera un plazo mínimo de protección de 10 años $^{63}$. En Chile, el plazo también es de 20 años pero se considera la demora administrativa injustificada, lo que implica que no habría plazos mínimos de protección, ya que se consideraría

vos a la propiedad industrial, art. 18. Disponible en: http://www.wipo.int/wipolex/es/details. jsp?id $=515$

59 Gobierno de Chile, Ley 19.039 sobre propiedad industrial (texto refundido, coordinado y sistematizado aprobado por el Decreto Ley 3) art. 37-38 (2012). Disponible en: http://www. wipo.int/wipolex/es/text.jsp?file_id=175347

60 Gobierno de Chile, Ley 19.039 sobre propiedad industrial (texto refundido, coordinado y sistematizado aprobado por el Decreto Ley 3) art. 51,1 (2012). Disponible en: http://www. wipo.int/wipolex/es/text.jsp?file_id=175347

61 Gobierno de Chile, Ley 19.039 sobre propiedad industrial (texto refundido, coordinado y sistematizado aprobado por el Decreto Ley 3) art. 51,2 (2012). Disponible en: http://www. wipo.int/wipolex/es/text.jsp?file_id=175347

62 Gobierno de Chile, Ley 19.039 sobre propiedad industrial (texto refundido, coordinado y sistematizado aprobado por el Decreto Ley 3) art. 95-96 (2012). Disponible en: http://www. wipo.int/wipolex/es/text.jsp?file_id=175347

63 Gobierno de Brasil, Ley 9.279 de 14 de mayo de 1996. Regula derechos y obligaciones relativos a la propiedad industrial, art. 40. Disponible en: http://www.wipo.int/wipolex/es/details. jsp?id=515 
la protección por vía administrativa ${ }^{64}$. Debido a la modificación de la Ley en 2012, que la adapta a las exigencias del TCP, se otorga la posibilidad de solicitar la restauración de los derechos de prioridad hasta dos meses después de vencido el plazo, tanto para patentes como para modelos de utilidad ${ }^{65}$.

En cuarto lugar, se observó la aparición de nuevos objetos de protección; pero se esperaba encontrar un mayor tipo de formas de protección en la legislación chilena. Al respecto, la ley chilena considera el secreto industrial como una forma de protección de propiedad industrial, algo que no hace la legislación brasileña; es más específica en cuestiones de denominación de origen e indicaciones geográficas; e incorpora las topografías de circuitos integrados; algo que en Brasil hace una legislación posterior.

Llama la atención el primer artículo de la ley chilena que deja abierta la posibilidad de nuevas formas de protección al señalar: "otros títulos de protección que la ley pueda establecer"

Finalmente, se analiza la rigurosidad de las leyes respecto a la tipificación de delitos y las sanciones establecidas. Acá se observó el único comportamiento contrario al esperado, pues se esperaba encontrar una legislación chilena mucho más rigurosa; en realidad, es lo contrario. En ambos casos, para la copia no autorizada de un producto protegido la tipificación de los delitos es equivalente; pero en Brasil las sanciones al respecto son penas de cárcel (de hasta un año); y multas de hasta 5 millones de dólares; para el caso de Chile, exclusivamente multas con un monto máximo de 150.000 dólares.

Puede decirse que la legislación chilena más reciente en al menos cuatro aspectos responde a las exigencias de los acuerdos comerciales de propiedad intelectual que este país ha firmado: otorga derechos más amplios a los titulares, establece menos restricciones, amplía los tiempos y los objetos de protección.

64 Gobierno de Chile, Ley 19.039 sobre propiedad industrial (texto refundido, coordinado y sistematizado aprobado por el Decreto Ley 3) art. 53 bis, 1, 2, 3, 4 y 5 (2012). Disponible en: http://www.wipo.int/wipolex/es/text.jsp?file_id=175347

65 Gobierno de Chile, Ley 19.039 sobre propiedad industrial (texto refundido, coordinado y sistematizado aprobado por el Decreto Ley 3) art. 116, 117 (2012). Disponible en: http://www. wipo.int/wipolex/es/text.jsp?file_id=175347

66 Gobierno de Chile, Ley 19.039 sobre propiedad industrial (texto refundido, coordinado y sistematizado aprobado por el Decreto Ley 3) art. 1 (2012). Disponible en: http://www.wipo. int/wipolex/es/text.jsp?file_id=175347 


\section{G. Efectos sobre las políticas públicas}

En la medida en que las políticas públicas de propiedad industrial estén conectadas con estrategias nacionales de innovación y desarrollo, es esperable que esto se ponga de manifiesto en diversas instancias institucionales, por lo que una primera categoría de observación es la presencia de la propiedad industrial en el aparato gubernamental de ambos países.

En Brasil, el Instituto Nacional de Propiedad Industrial, INPI, es un organismo dependiente del Ministerio de Desarrollo, Industria y Comercio Exterior y que establece procesos de coordinación y consulta con diversos ministerios entre los que destacan el Ministerio de Planificación, Presupuesto y Gestión; el Ministerio de Ciencia, Tecnología e Innovación; el de Agricultura, Ganadería y Abastecimiento; el de Minas y Energía; el de Salud; el de Cultura; y el de Comunicaciones ${ }^{67}$.

Esta coordinación está organizada a partir de una serie de políticas de Estado orientadas al desarrollo económico y productivo, y a la innovación tecnológica. Se destaca la creación del Sistema de Propiedad Intelectual que busca optimizar los recursos estatales destinados a propiedad intelectual que provienen de la Política de Desarrollo Productivo (PDP) y con el Plan Plurianual (2008-2011). El INPI se coordina además con la Política Industrial Tecnológica y de Comercio Exterior; y con la Política de Desarrollo de Biotecnología. Finalmente, todas las decisiones internacionales en la materia son definidas por el Grupo Interministerial de Propiedad Intelectual ${ }^{68}$.

Todo lo anterior permite señalar que las políticas de propiedad industrial en Brasil están interconectadas y coordinadas con un marco más amplio de políticas de innovación y desarrollo:

La propiedad intelectual constituye una contribución para las políticas sectoriales del Ministerio de Desarrollo, Industria y Comercio Exterior, centrada,

67 Instituto Nacional de Propriedade Industrial, INPI, Brasil, Balanço \& Perspectivas (Edições INPI, 2009).

68 Instituto Nacional de Propriedade Industrial, INPI, Brasil, Relatório de Gestão (Edições INPI, 2009). Disponible en: http://www.amcham.com.br/repositorio-de-arquivos/relatorios-inpi/ relatorio-la-edicao 
en esencia, en la promoción de la innovación y de la inserción de las empresas brasileñas en mercados dinámicos ${ }^{69}$.

En Chile, el Instituto Nacional de Propiedad Industrial, INAPI, es un organismo dependiente del Ministerio de Economía. Sin embargo, se pudo constatar que la existencia de procesos de coordinación entre el INAPI y otros organismos públicos es mucho más limitada. Su principal vinculación es con el Consejo Nacional de Innovación para la Competitividad, y con algunos programas específicos de otros organismos públicos como el Innova-CORFO, de la Corporación de Fomento de la Producción, y con otros organismos subnacionales ${ }^{70}$.

La mención de la propiedad intelectual e industrial en políticas de desarrollo, producción e innovación es muy limitada, teniendo su principal expresión en la Estrategia Nacional de Innovación para la Competitividad, pero sin lineamientos concretos que establezcan orientaciones. La importancia otorgada a la propiedad industrial como parte de políticas de innovación y desarrollo, es mucho más reducida en Chile.

Tanto en Brasil como en Chile, los mencionados institutos han experimentado recientemente un fuerte proceso de modernización institucional. El INPI en Brasil se moderniza para adaptarse a las exigencias de las nuevas políticas de desarrollo, producción e innovación que se inician en el gobierno de Luiz Inácio Lula da Silva a partir de $2004^{71}$. Esta modernización tiene como uno de sus objetivos principales la reducción de los tiempos de tramitación (la obtención de una patente puede demorar el doble de tiempo que en Chile, aunque se recibe un volumen de solicitudes mucho mayor), por lo que se ha invertido en contratación de personal y adquisición de nuevas tecnologías.

69 Instituto Nacional de Propriedade Industrial, INPI, Brasil, Relatório de Gestão, 106 (Edições INPI, 2009). Disponible en: http://www.amcham.com.br/repositorio-de-arquivos/relatorios-inpi/relatorio-la-edicao

70 Instituto Nacional de Propiedad Industrial, INAPI, Chile, Informe de instalación (Ediciones INAPI, 2009).

71 Instituto Nacional de Propriedade Industrial, INPI, Brasil, Balanço \& Perspectivas (Edições INPI, 2009). 
La única mención a que este proceso de modernización tuviera qué ver con exigencias internacionales se hace en relación con el cumplimiento de acuerdos en el ámbito de las marcas ${ }^{72}$.

En el caso chileno, el Instituto no existía antes de la reciente ley de propiedad industrial. Anteriormente solo había una oficina con muy reducidas capacidades de gestión. Uno de los desafíos de la instalación del INAPI es también la reducción de los tiempos de tramitación, aunque llama la atención que, a lo largo de la década pasada, según datos de $\operatorname{INAPI}^{73}$ (2011), un 91,6\% de las patentes de invención registradas en Chile son de extranjeros, por lo que la contratación de nuevos peritos en ámbitos como la farmacéutica, la bioquímica o la biotecnología no tiene una vinculación clara con las áreas productivas declaradas como estratégicas por el país ${ }^{74}$.

Respecto a que los procesos de modernización respondan a exigencias internacionales, hay compromisos de modernización vinculados con el Tratado de Cooperación en materia de Patentes, el Tratado de Derecho de Marcas, así como también compromisos de modernización vinculados con ADPIC, y con acuerdos establecidos con Estados Unidos y la Unión Europea.

En ambos casos, entre las funciones desarrolladas por los institutos, un ámbito prioritario es el de la tramitación eficiente de la propiedad industrial. En Brasil, se destacan otras áreas de acción relevantes, como el vínculo o difusión de la importancia de la propiedad industrial hacia la sociedad, el perfeccionamiento en la materia orientado a empresas, la formación de posgrado e investigación en la materia, así como el soporte empresarial en procesos de transferencia tecnológica. Se destacan además una buena coordinación con las universidades brasileñas (las principales generadoras de innovación tecnológica en el país), y fuertes nexos internacionales con diversos organismos de propiedad industrial, siendo relevante la declarada función estratégica de promoción de la propiedad intelectual con países no desarrollados, estableciendo vínculos con países africanos (Angola, Cabo Verde, Guinea Bissau,

72 Instituto Nacional de Propriedade Industrial, INPI, Brasil, Balanço \& Perspectivas (Edições INPI, 2009).

73 Instituto Nacional de Propiedad Industrial, INAPI, Chile, Cooperación INAPI.

74 Las políticas de desarrollo productivo del país han establecido clusters principalmente en áreas de recursos naturales, como la alimentaria, acuícola y minera, pero también el sector servicios, como turismo y servicios globales. 
Mozambique, Santo Tomé y Príncipe), y sudamericanos (Bolivia, Perú y Chile).

En el caso del INAPI en Chile, la función primordial es también la tramitación efectiva, y se considera adicionalmente la necesidad de generar procesos de transferencia tecnológica hacia los actores del sector. Los vínculos nacionales, en especial con las universidades, son todavía incipientes, debido a que las capacidades de innovación y transferencia no están plenamente desarrolladas. Los vínculos internacionales, generalmente con oficinas de propiedad industrial de países desarrollados, son incipientes. 


\section{CONCLUSIONES: ORIENTADOS A UNA MAYOR AUTONOMÍA PARA POTENCIAR EL DESARROLLO}

En las páginas anteriores se ha procurado mostrar la existencia de diferencias significativas en materia de propiedad industrial entre Brasil y Chile. Estas diferencias se manifiestan en dos espacios de acción diferentes: el internacional vinculado con la firma de diversos tratados internacionales, y el nacional, relacionado con las respectivas legislaciones y políticas públicas en la materia.

Se ha podido constatar que ambos países siguen estrategias de integración internacional muy diversas, en la medida en que Brasil mantiene una posición más estratégica respecto a la relevancia de la propiedad industrial en función de sus procesos de desarrollo social y económico; y para el caso chileno, responde más bien a un "anexo" de acuerdos cuya prioridad es la integración comercial. Uno de los factores clave en el mantenimiento de estas diferencias estratégicas es el tiempo de la firma e integración a los diversos acuerdos internacionales; llama la atención que los firmados por Brasil después del año 2000 son mínimos en comparación con los mayores compromisos adquiridos por Chile recientemente.

Estas diferencias en la vinculación internacional se ponen de manifiesto en una serie de divergencias clave en los cuerpos legales de propiedad industrial de ambos países. Se pudo constatar además, que estas diferencias también tienen una expresión en las políticas públicas de propiedad intelectual e industrial. Mostramos que la propiedad industrial tiene un importante papel en las políticas de innovación en Brasil, que promueve abiertamente el desarrollo de mercados tecnológicos. En Chile, en cambio, las políticas siguen orientadas hacia los recursos naturales y más recientemente a los servicios, espacios en los cuales la propiedad industrial tiene un impacto limitado, en la medida en que no involucra nuevos actores y no diversifica la producción.

La posición privilegiada de Brasil —en términos de su peso internacional - y su mercado interno le han permitido una mayor autonomía internacional que ha posibilitado un mayor crecimiento, y por lo tanto, ha generado incentivos para la innovación, la protección del conocimiento y su transferencia al mercado. Chile 
ha privilegiado integrarse desde una lógica de apertura comercial, pero que limita fuertemente sus capacidades de generar estrategias propias de desarrollo por lo que la propiedad industrial tiene valor principalmente para agentes externos que tienen capacidad de gestión en los mercados globales del conocimiento. 


\section{BIBLIOGRAFÍA}

\section{Libros}

Abarza, Jacqueline \& Katz, Jorge, Los derechos de propiedad intelectual en el mundo de la $O M C$ (Naciones Unidas, Comisión Económica para América Latina y el Caribe, CEPAL, Santiago de Chile, 2002). Disponible en: http://portal.concytec. gob.pe/images/stories/images2012/portal/areas-institucion/dag/curso-politicasctei/propiedad-intelectual/1.pdf

Becerra-Ramírez, Manuel, La propiedad intelectual en transformación (Ediciones Universidad Nacional Autónoma de México, UNAM, México, 2004). Disponible en: http://biblio.juridicas.unam.mx/libros/libro.htm?1=1526

Castells, Manuel, Globalización, desarrollo y democracia: Chile en el contexto mundial (Fondo de Cultura Económica, FCE, Santiago de Chile, 2005).

DíAz, Álvaro, América Latina y el Caribe: la propiedad intelectual después de los tratados de libre comercio (Naciones Unidas, Comisión Económica para América Latina y el Caribe, CEPAL, Santiago de Chile, 2008). Disponible en: http://repositorio. cepal.org/bitstream/handle/11362/2526/S0600728_es.pdf?sequence=1

Marsh, David \& Stoker, Gerry, Theory and Methods in Political Science (Palgrave MacMillan, New York, 1995).

Sartori, Giovanni \& Morlino, Leonardo (eds.), La comparación en las ciencias sociales (Alianza Editorial, Madrid, 1996).

Sercovich, Francisco, Tratados de libre comercio, derechos de propiedad intelectual y brecha de desarrollo: dimensiones de política desde una perspectiva latinoamericana (Naciones Unidas, Comisión Económica para América Latina y el Caribe, CEPAL, México, 2008). Disponible en: http://repositorio.cepal.org/bitstream/ handle/11362/4877/S0800444_es.pdf?sequence=1

\section{Contribuciones en obras colectivas}

Martínez-Piva, Jorge Mario, Capítulo II. La protección de los derechos de propiedad intelectual, la innovación y el desarrollo, en Generación y protección del conocimiento: propiedad intelectual, innovación y desarrollo económico, 59-90 (Jorge Mario Martínez-Piva, Naciones Unidas, Comisión Económica para América Latina y el Caribe, CEPAL, México, 2008). Disponible en: http://www. cepal.org/es/publicaciones/2873-generacion-y-proteccion-del-conocimientopropiedad-intelectual-innovacion-y

\section{Revistas}

Chang, Ha-Joon, Intellectual Property Rights and Economic Development. Historical Lessons and Emerging Issues, 2 Journal of Human Development, 2, 287-309 (2001).

Coriat, Benjamin, El régimen de la propiedad intelectual y la innovación, 233 Realidad 
Económica, 49-65 (2008).

RozAnski, Félix, El valor de la propiedad intelectual en los países en desarrollo, 28 Interciencia, 2, 105-110 (2003). Disponible en: http://www.interciencia.org/ v28_02/rozanski

\section{Normatividad internacional}

Acuerdo Interino entre la Comunidad Europea y Chile, 18 de noviembre de 2002, Bruselas. Disponible en: http://www.wipo.int/edocs/lexdocs/treaties/es/cl-ec/ trt_cl_ec.pdf

Biblioteca del Congreso Nacional de Chile, Historia de la Ley No 19.996. Modifica la Ley No 19.039 sobre propiedad intelectual. Disponible en: http://www.leychile.cl/ Navegar/scripts/obtienearchivo?id=recursoslegales/10221.3/4216/1/HL19996.pdf

Biblioteca del Congreso Nacional de Chile, Historia de la Ley No 19.039. Establece normas aplicables a los privilegios industriales y protección de los derechos de propiedad industrial. Disponible en: http://www.leychile.cl/Navegar/scripts/obt ienearchivo?id=recursoslegales/10221.3/12821/5/HL19039.pdf

Convención General Interamericana sobre Protección Marcaria y Comercial, 20 de febrero de 1929, Washington. Disponible en: http://www.wipo.int/wipolex/es/ details.jsp?id=12625

Convención Interamericana sobre el Derecho de Autor en Obras Literarias, Científicas y Artísticas, 22 de junio de 1946, Washington. Disponible en: http://www.wipo. int/wipolex/es/other_treaties/details.jsp?group_id=21\&treaty_id=378

Gobierno de Brasil, Ley 9.279 de 14 de mayo de 1996. Regula derechos y obligaciones relativos a la propiedad industrial. Disponible en: http://www.wipo.int/wipolex/ es/details.jsp?id=515

Gobierno de Brasil, Ley 11.484 del 31 de mayo de 2007 (topografías de circuitos integrados). Disponible en: http://www.wipo.int/wipolex/es/details.jsp?id=8307

Gobierno de Chile, Ley 19.039 sobre propiedad industrial (texto refundido, coordinado y sistematizado aprobado por el Decreto Ley 3) (2012). Disponible en: http:// www.wipo.int/wipolex/es/text.jsp?file_id=175347

Protocolo sobre Uniformidad del Régimen Legal de los Poderes, 17 de febrero de 1940, Washington. Disponible en: http://www.wipo.int/wipolex/es/other_treaties/ details.jsp?group_id=22\&treaty_id=389

Tratado de Libre Comercio entre Estados Unidos y Chile, 6 de junio de 2003. Disponible en: http://www.direcon.gob.cl/detalle-de-acuerdos/?idacuerdo $=6277$

Tratado sobre el Derecho de Patentes (PLT), adoptado por la Conferencia Diplomática el 1 de junio de 2000. Disponible en: http://www.wipo.int/patent-law/es/plt.htm

Unión Internacional para la Protección de las Obtenciones Vegetales, UPOV, Convenio Internacional para la Protección de las Obtenciones Vegetales, adoptado por una Conferencia Diplomática, el 2 de diciembre de 1961, en París. Disponible en: http://www.upov.int/upovlex/es/upov_convention.html 


\section{Documentos, informes, reportes}

Banco Interamericano de Desarrollo, BID, Ciencia, tecnología e innovación en América Latina y el Caribe: un compendio estadístico de indicadores (Banco Interamericano de Desarrollo, New York, 2010). Disponible en: http://www.iadb.org/es/ publicaciones/detalle,7101.html?id=67649

Cimoli, Mario \& Primi, Annalisa, Technology and Intellectual Property: A Taxonomy of Contemporary Markets for Knowledge and their Implications for Development (Naciones Unidas, Comisión Económica para América Latina y el Caribe, CEPAL, Santiago de Chile, 2007). Disponible en: http://citeseerx.ist.psu.edu/ viewdoc/download?doi=10.1.1.121.5414\&rep=rep1\&type $=$ pdf

Gobierno de Brasil - Organización Mundial del Comercio, OMC, Examen de la legislación. Brasil (Organización Mundial del Comercio, OMC, 2004). Disponible en: https://docs.wto.org/dol2fe/Pages/FE_Search/FE_S_S006.aspx?Query=@, Symbol=\%20ip/q*\%20and $\% 20 \% 20 @$ Symbol= $\% 20$ bra $\&$ Language $=$ SPANISH $\&$ Context $=$ FomerScriptedSearch\&languageUIChanged=true\#

Gobierno de Chile, Dirección General de Relaciones Económicas Internacionales, Acuerdos comerciales. Disponible en: http://www.direcon.gob.cl/acuerdoscomerciales/

Gobierno de Chile - Organización Mundial del Comercio, OMC, Examen de legislación. Chile (Organización Mundial del Comercio, OMC, 2001). Disponible en: https:// docs.wto.org/dol2fe/Pages/FE_Search/FE_S_S006.aspx?Query=@Symbol=\%20 $\mathrm{ip} / \mathrm{q} * \% 20$ and $\% 20 \% 20 @$ Symbol=\%20chl $\&$ Language $=$ SPANISH\&Context $=$ Fom erScriptedSearch\&languageUIChanged $=$ true\#

Instituto Nacional de Propiedad Industrial, INAPI, Chile, Informe de instalación (Ediciones INAPI, 2009).

Instituto Nacional de Propiedad Industrial, INAPI, Chile, Cooperación INAPI.

Instituto Nacional de Propriedade Industrial, INPI, Brasil, Balanço \& Perspectivas (Edições INPI, 2009).

Instituto Nacional de Propriedade Industrial, INPI, Brasil, Relatório de Gestão (Edições INPI, 2009). Disponible en: http://www.amcham.com.br/repositorio-de-arquivos/ relatorios-inpi/relatorio-la-edicao

International Center for Trade and Sustainable Development, ICTSD, Brasil: $O M C$ reafirma victoria en caso del algodón contra los EE.UU. Disponible en: http:// ictsd.org/i/news/puentesquincenal/10188/

Organización Mundial de Comercio, OMC, Declaración relativa al Acuerdo sobre los ADPIC y la salud pública. Disponible en: http://www.wto.org/spanish/thewto_s/ minist_s/min01_s/mindecl_trips_s.htm

Organización Mundial de Comercio, OMC, Estados Unidos - Subvenciones al algodón americano (Upland). Disponible en: http://www.wto.org/spanish/tratop_s/ dispu_s/cases_s/ds267_s.htm

Organización Mundial de Comercio, OMC, Solución de diferencias: las diferencias. Índice de diferencias por Acuerdo. Disponible en: http://www.wto.org/spanish/ tratop_s/dispu_s/dispu_agreements_index_s.htm?id=A26\#selected_agreement 
Organización Mundial de Comercio, OMC, Solución de diferencias: las diferencias. DS199. Disponible en: http://www.wto.org/spanish/tratop_s/dispu_s/cases_s/ ds199_s.htm

Organización Mundial de Comercio, OMC, Solución de diferencias: las diferencias. DS224. Disponible en: http://www.wto.org/spanish/tratop_s/dispu_s/cases_s/ ds224_s.htm

Organización Mundial de Comercio, OMC, Solución de diferencias: las diferencias. DS409. Disponible en: http://www.wto.org/spanish/tratop_s/dispu_s/cases_s/ ds409_s.htmOrganización Mundial de la Propiedad Intelectual, WIPO Lex. Disponible en: http://www.wipo.int/wipolex/es/

Organización Mundial de Propiedad Intelectual, OMPI, World Intellectual Property Indicators (2013). Disponible en: http://www.wipo.int/ipstats/en/wipi/

Organización Mundial de la Propiedad Intelectual, OMPI, WIPO Lex. Disponible en: http://www.wipo.int/wipolex/es/

Organización para la Cooperación y el Desarrollo Económicos, OCDE, Chile lidera América Latina y supera a 10 países OCDE en ranking mundial de Sociedad de la Información. Disponible en: http://www.subtel.gob.cl/chile-lidera-america-latinay-supera-a-10-paises-ocde-en-ranking-mundial-de-sociedad-de-la-informacion/, http://www.subtel.gob.cl/index.php?option=com_content\&view=article\&id= 3197\%3Achile-lidera-america-latina-y-supera-a-10-paises-ocde-en-rankingmundial-de-sociedad-de-la-informacion-\&catid=95\%3Aservicios-telecomuni caciones\&Itemid=786\&lang=es

Senado de Chile, Boletín 6355-01. Disponible en: http://www.senado.cl/appsenado/ templates/tramitacion/index.php\# 
